\title{
Peripancreatic pseudoaneurysms: a management-based classification system
}

\author{
Tony C. Y. Pang $\cdot$ Richard Maher $\cdot$ \\ Sivakumar Gananadha · Thomas J. Hugh • \\ Jaswinder S. Samra
}

Received: 15 September 2013/ Accepted: 9 January 2014/Published online: 12 February 2014

(C) The Author(s) 2014. This article is published with open access at Springerlink.com

\begin{abstract}
Background Peripancreatic pseudoaneurysms can arise in a number of different clinical settings but are associated mostly with pancreatitis and pancreatobiliary surgery. The aim of this study is to review the current literature and to propose a management classification system based on the pathophysiological processes and the exact anatomical site of peripancreatic pseudoaneurysms.

Methods A systematic review of the literature from 1995 to 2012 was performed. Articles on studies describing peripancreatic pseudoaneurysms in the setting of pancreatitis or major hepatic or pancreatic surgery with more than ten patients were included. Seventeen eligible studies were identified and reviewed.

Results The demographic characteristics of the patients in all studies were similar with a predominance of males and a mean age of 55 years. The overall mortality rate varied greatly among the studies, ranging from 0 to $60 \%$. Embolisation was the first line of management in the majority
\end{abstract}

T. C. Y. Pang · S. Gananadha · T. J. Hugh · J. S. Samra $(\bowtie)$ Upper GI Surgical Unit, Royal North Shore Hospital and North Shore Private Hospitals, University of Sydney, St Leonards, NSW 2065, Australia

e-mail: jaswinder.samra@optusnet.com.au

S. Gananadha

e-mail: sivakumar.gananadha@act.gov.au

T. C. Y. Pang · T. J. Hugh $\cdot$ J. S. Samra

Discipline of Surgery, Sydney Medical School, University of Sydney, Sydney 2000, Australia

\section{R. Maher}

Department of Radiology, Royal North Shore Hospital and North Shore Private Hospitals, University of Sydney,

St Leonards, NSW 2065, Australia of the studies, with surgery reserved for failed embolisation or for haemodynamically unstable cases. Embolisation of the hepatic artery or its branches was associated with high rates of morbidity (56\%) and hepatic failure (19\%). More recent studies show that stents are used increasingly for vessels that cannot be embolised safely. Late bleeding, a major cause of mortality and morbidity, is generally underreported. The proposed classification system is based on three factors: (1) the type of artery from which the pseudoaneurysm arises, (2) whether communication with the gastrointestinal tract is present, and (3) whether there is high concentration of pancreatic juice at the bleeding site. Conclusion The management of peripancreatic pseudoaneurysms usually comprises a combination of interventional radiology and surgery and this may be assisted by a logical classification system.

Keywords Pseudoaneurysm - Pancreatoduodenectomy · Chronic pancreatitis - Acute pancreatitis

Managing peripancreatic pseudoaneurysms is complex and challenging. Advances in imaging technology and interventional radiology have had an enormous impact on both the diagnosis and the treatment of this condition. Pseudoaneurysms can arise in a number of different clinical settings but are associated mostly with pancreatitis and pancreatobiliary surgery [1].

Initially, the high mortality associated with this condition is due to uncontrolled torrential bleeding. If the patient survives this initial phase there is a risk of rebleeding, which can occur from days to years after the initial presentation. The additional late mortality may be substantial if patients are not managed appropriately during their initial presentation. Treatment strategies should be based on the mechanisms that lead to the formation of pseudoaneurysms and 
to the ongoing pathophysiological processes that result in rebleeding.

Currently, the best method of assessing a relatively stable patient is a computerised tomography (CT) angiogram with or without a formal angiogram [2]. This usually provides an accurate diagnosis but also allows, if required, radiological intervention by embolisation of the feeding vessel or the pseudoaneurysm itself. If visceral ischaemia distal to the pseudoaneurysm is a concern, a stent may be placed [1, 3]. Patients with haemodynamic instability may need immediate surgical intervention, although this can be fraught with danger even in experienced hands.

There are no data on definitive long-term management strategies for this condition. This is partly due to its low rate of occurrence but also because of a poor understanding of the pathophysiological processes involved. The mechanisms by which most peripancreatic pseudoaneurysms are formed are thought to be related to the underlying inflammation, the presence of pancreatic juices, and the subsequent infection [4]. In postoperative patients, pseudoaneurysms are often associated with intra-abdominal sepsis due to anastomotic leakage [5]. Unless these underlying processes are dealt with adequately, the risk of further bleeding can be substantial.

The aim of this article is to review the literature regarding pancreatic pseudoaneurysms with an emphasis on current treatment practices. We also propose a management classification system based on the pathophysiological processes and the exact anatomical site of the pseudoaneurysm. A classification such as this may help with decision making during initial and definitive management to minimise the risk of rebleeding and to reduce late mortality.

\section{Methods}

\section{Search strategy}

A literature search was performed using "keywords" and "headings" in Medline and EMBASE limited to publications from 1995 to 2011. Keyword searches of panc*, surg*, resect*, and neoplasm* and heading searches of pseudoaneurysm, pancreatitis, operation, cancer, and neoplasm were used along with Boolean operators.

Due to the variability of the descriptions of peripancreatic arterial haemorrhagic complications, articles were eligible only if they included patients with peripancreatic pseudoaneurysms, "aneurysms," or peripancreatic arterial bleeding detected on angiography. Non-English articles, single case reports, case series with fewer than ten patients (even if more than ten pseudoaneurysms were treated), and reviews were excluded. Case series with patients with mixed pathologies (e.g., haemosuccus pancreaticus, suspected pancreatic bleeding with no definitive angiographic findings [6], or delayed postpancreatectomy haemorrhage) were included only if adequate clinical information about patients with the above eligible pathology could be extracted or if patients were selected such that only those with visceral arterial bleeding was included. Articles describing visceral pseudoaneurysms that were not associated with pancreatitis or pancreatobiliary surgery (e.g., vasculitis) were also excluded [7].

Twenty studies were identified during the initial literature search and 17 met the eligibility criteria. Two pairs of studies were most likely from the same institution and therefore only the more recent study was included in the analysis [8, 9]. One additional study was excluded due to insufficient information [10].

\section{Statistical analysis}

All statistical analyses and charting were performed with Microsoft Excel 2010 for Windows (Microsoft Corp., Redmond, WA) and Stata SE version 11.2 for Windows (StataCorp., College Station, TX). Due to the heterogeneity of the patient population and the treatment strategies, no inferential statistical analyses were performed. Only descriptive statistical analyses are presented and discussed.

\section{Results and discussion}

Pancreatic pseudoaneurysms are relatively rare and the exact incidence is difficult to measure due to the varying aetiologies. The most common associations are with pancreatitis and major pancreatobiliary surgery. The relative incidence of these two aetiologies is not clear because a significant number of studies present either type but not both. Pseudoaneurysms can occur in both acute and chronic pancreatitis; however, they are more common in chronic pancreatitis and are often associated with pseudocysts [11]. It is thought that pancreatic juice within the pseudocyst causes enzymatic degradation of the adjacent arterial wall, with weakness and rupture leading to pseudoaneurysm formation. In the setting of major pancreatobiliary surgery, pseudoaneurysm formation is thought to be associated with either skeletonisation of vessels or complicating bilio- or pancreaticoenteric anastomotic leak [5, 12, 13].

The studies reviewed are listed in Table 1. The demographic characteristics of the patients in all studies were similar, with a predominance of males and a mean age 55 (45-66) years (excluding the studies De Perrot et al. [14] and Lee [15]). The mean age of the surgical patients who developed pseudoaneurysms was older than that of the patients with pancreatitis (range of means: 58-66 vs. 
Table 1 Demographic and mortality data

\begin{tabular}{|c|c|c|c|c|c|c|c|c|c|c|c|c|}
\hline & \multirow[t]{2}{*}{ Postop $^{a}$} & \multirow[t]{2}{*}{ Pancr $^{\mathrm{a}}$} & \multirow[t]{2}{*}{ Total $^{\mathrm{a}}$} & \multirow[t]{2}{*}{ Year } & \multirow[t]{2}{*}{$\mathrm{Age}^{\mathrm{b}}$} & \multirow{2}{*}{$\begin{array}{l}\text { Sex } \\
(\mathrm{M}: \mathrm{F})\end{array}$} & \multicolumn{4}{|c|}{ Presentation $^{c}$} & \multirow{2}{*}{$\begin{array}{l}\text { Sentinel } \\
\text { bleed }^{c}\end{array}$} & \multirow[t]{2}{*}{ Mortality $^{\mathrm{c}, \mathrm{g}}$} \\
\hline & & & & & & & $\begin{array}{l}\text { Intra- } \\
\text { abdominal }^{\text {bleed }}\end{array}$ & $\begin{array}{l}\text { GI } \\
\text { bleed }^{\mathrm{e}}\end{array}$ & $\begin{array}{l}\text { Occult/ } \\
\text { shock }^{f}\end{array}$ & Pain & & \\
\hline \multicolumn{13}{|c|}{ Postoperative only } \\
\hline $\begin{array}{l}\text { Okuno et al. } \\
\text { [13] }\end{array}$ & 14 & 0 & 14 & 1985-1998 & $60(40-72)$ & $11: 3$ & $10(71)$ & $4(29)$ & - & $10(71)$ & $11(79)$ & $4(29)$ \\
\hline $\begin{array}{l}\text { Fujii et al. } \\
\text { [12] }\end{array}$ & 13 & 0 & 13 & 1993-2005 & 66 (SD 10) & $10: 3$ & - & - & - & - & - & $7(54)$ \\
\hline $\begin{array}{l}\text { Miura et al. } \\
\text { [5] }\end{array}$ & 15 & 0 & 15 & 1981-2007 & $65(50-82)$ & $11: 4$ & - & - & - & - & $7(47)$ & $9(60)$ \\
\hline Lee [15] & 27 & 0 & 27 & 1995-2007 & - & - & $13(48)$ & $\begin{array}{l}10 \\
(37)\end{array}$ & $6(22)$ & - & $21(78)$ & $6(22)$ \\
\hline $\begin{array}{l}\text { Schäfer et al. } \\
\text { [30] }\end{array}$ & 18 & 0 & 18 & 1998-2009 & $58(39-82)$ & $11: 7$ & $4(22)$ & 7 (39) & $9(50)$ & $2(11)$ & - & $6(33)$ \\
\hline $\begin{array}{l}\text { Lee et al. } \\
\text { [31] }\end{array}$ & 27 & 0 & 27 & 2003-2011 & $64(48-86)$ & $20: 7$ & $20(74)$ & $\begin{array}{l}13 \\
(48)\end{array}$ & - & - & $22(82)$ & $6(22)$ \\
\hline \multicolumn{13}{|c|}{ Pancreatitis only } \\
\hline $\begin{array}{l}\text { Gambiez } \\
\text { et al. [37] }\end{array}$ & 0 & 14 & 14 & 1983-1994 & $46(32-60)$ & $11: 3$ & $2(14)$ & $8(57)$ & $4(29)$ & - & N/A & $2(14)$ \\
\hline $\begin{array}{l}\text { De Perrot } \\
\text { et al. [14] }\end{array}$ & 0 & 10 & 10 & 1978-1997 & $\begin{array}{r}44 \text { (med) } \\
(28-61)\end{array}$ & $7: 3$ & - & - & $9(90)$ & $\begin{array}{l}10 \\
(100)\end{array}$ & N/A & $1(10)$ \\
\hline $\begin{array}{c}\text { Carr et al. } \\
{[38]}\end{array}$ & 0 & 16 & 16 & 1988-1998 & 45 (23-67) & $11: 5$ & - & - & - & - & N/A & 3 (19) \\
\hline $\begin{array}{l}\text { Beattie et al. } \\
\text { [23] }\end{array}$ & 0 & $13^{\mathrm{h}}$ & 13 & 1995-1999 & $57(25-81)$ & $11: 8$ & - & - & - & - & N/A & $3(21)$ \\
\hline $\begin{array}{l}\text { Bergert et al. } \\
\text { [11] }\end{array}$ & 0 & 35 & 35 & 1993-2004 & $51(28-75)$ & $28: 7$ & - & $\begin{array}{l}16 \\
(46)\end{array}$ & $15(43)$ & $\begin{array}{l}35 \\
(100)\end{array}$ & N/A & $7(20)$ \\
\hline $\begin{array}{l}\text { Zhou et al. } \\
\text { [40] }\end{array}$ & 0 & 19 & 19 & $2000-2003$ & $43(26-61)$ & $10: 9$ & - & - & $5(26)$ & - & - & - \\
\hline $\begin{array}{l}\text { Lermite et al. } \\
{[16]}\end{array}$ & 0 & 17 & 17 & $1981-2005$ & $57(35-70)$ & $15: 2$ & - & $\begin{array}{l}13 \\
(76)\end{array}$ & $2(12)$ & $2(12)$ & N/A & $0(0)$ \\
\hline $\begin{array}{l}\text { Udd et al. } \\
\text { [25] }\end{array}$ & 0 & 33 & 33 & 1993-2005 & $54(42-78)$ & $27: 6$ & - & $\begin{array}{l}17 \\
(52)\end{array}$ & - & $22(67)$ & N/A & $2(6)$ \\
\hline $\begin{array}{l}\text { Sethi et al. } \\
\text { [27] }\end{array}$ & 0 & 16 & 16 & 2000-2007 & $52(21-71)$ & $11: 5$ & $2(13)$ & $8(50)$ & $10(63)$ & $14(88)$ & N/A & $0(0)$ \\
\hline \multicolumn{13}{|c|}{ Both pancreatitis and postoperative } \\
\hline $\begin{array}{l}\text { Zyromski } \\
\text { et al. [3] }\end{array}$ & 13 & 24 & 37 & $1995-2005$ & $\begin{array}{r}\text { Postop 62 } \\
\text { (SD 15) }\end{array}$ & $21: 16$ & 7 (19) & $\begin{array}{l}14 \\
(38)\end{array}$ & $3(8)$ & $15(41)$ & $\begin{array}{r}12 / 13 \\
(92)\end{array}$ & $\begin{array}{l}\text { Postop } 4 \\
\text { (31) }\end{array}$ \\
\hline & & & & & $\begin{array}{l}\text { Pancr } 46 \\
\quad(\text { SD 11) }\end{array}$ & & & & & & & Pancr 1 (4) \\
\hline $\begin{array}{l}\text { Kalva et al. } \\
{[1]^{\mathrm{j}}}\end{array}$ & 9 & 12 & $23^{\mathrm{i}}$ & $1978-2010$ & $64(21-84)$ & $17: 6$ & $19(83)$ & $2(9)$ & $2(9)$ & - & $6(26)$ & \\
\hline
\end{tabular}

GI gastrointestinal, N/A not applicable, Pancr pancreatitis, Postop postoperative, SD standard deviation, - no data, med median

${ }^{\text {a }}$ Values are number $(n)$

b Values are mean (range)

c Values are number (percent)

${ }^{\mathrm{d}}$ Intra-abdominal bleed includes bleeding from drain as presenting symptom and massive distention

e Gastrointestinal bleed includes haematemesis, melaena, and haematochezia

${ }^{\mathrm{f}}$ Occult/shock is no obvious presenting symptoms apart from signs of blood loss, either acute or chronic (shock, anaemia)

g Mortality is 30-day or inpatient all-cause mortality

${ }^{\mathrm{h}}$ Article described 19 patients, but only 13 demonstrated angiographic evidence of bleeding or pseudoaneurysm ( 1 vasculitis, 5 negative angiograms). Age and sex distribution based upon the entire 19 patients described in the paper

${ }^{\mathrm{i}}$ Two patients were secondary to trauma

${ }^{\mathrm{j}}$ Kalva et al's study described 51 patients, but only 23 patients demonstrated a pseudoaneurysm or evidence of active extravasation 
44-57 years). Interestingly, young patients ( $<40$ years) were almost exclusively in the pancreatitis group. This age difference was confirmed by Zyromski et al. [3]; theirs was the only study that compared these two patient groups (mean age $=62$ vs. $46, P<0.007$ ).

\section{Presentation and outcome}

Pseudoaneurysms may rupture into the gastrointestinal tract (GIT), the peritoneal cavity, the pancreatic duct, or a pseudocyst. Bleeding into the GIT can occur directly or indirectly. The latter is often due to haemosuccus pancreaticus or haemobilia [3, 16], where patients present with haematemesis, haematochezia, or melaena. Those with extensive retroperitoneal haematoma, but without bleeding into the GIT, may present with pain only. In the studies reviewed, gastrointestinal bleeding was the most common presentation overall. In postoperative patients, intraabdominal bleeding was the most common presentation, reflecting the underlying pathophysiology. On the other hand, in patients with pancreatitis, pain was the most prominent presenting symptom (Table 1).

The onset of fresh bleeding from a drain following pancreatic surgery is an ominous sign suggestive of intraabdominal bleeding, including from a pseudoaneurysm. It is known as a sentinel bleed. Initial minor bleeding may be followed by more catastrophic blood loss and this occurs in up to $90 \%$ of cases $[5,15]$. The importance of a sentinel bleed was first highlighted by Sato et al. [17] who described it in all ten patients in their study with massive bleeding following pancreatectomy. More recent studies also suggested that this is frequently a warning sign of imminent and massive haemorrhage after pancreaticobiliary surgery $[18,19]$. Early angiography is recommended as this may allow intervention while the patient is still haemodynamically stable. On the other hand, some authors have found that despite awareness of this entity, identification of a sentinel bleed was not associated with a significant difference in mortality [20]. Unfortunately, it is unclear from this latter study whether specific interventions were undertaken in response to the bleeding. Overall, sentinel bleeding was noted in $47-92 \%$ of patients in the studies reviewed (Table 1).

The overall mortality rate in patients with bleeding peripancreatic pseudoaneurysms varied greatly among the studies, ranging from 0 to $60 \%$. The mortality rate for bleeding associated with pancreatitis $(0-21 \%)$ was lower compared with that for bleeding post-surgery (22-60\%). Unfortunately, few studies included patients from both groups, which prevented meaningful inferential statistical analysis. The study by Zyromski et al. [3] was the only one that compared the two groups and, indeed, found a statistically significant difference in mortality favouring the pancreatitis group ( $31 \%$ vs. $4 \%, P=0.04$ ). In the postpancreatitis group, there was a trend toward improvements in mortality, with the most recent studies reporting mortality rates of less than $10 \%$. This compares favourably with historical mortality rates (up to $30 \%$ ) for patients who underwent operative intervention for postpancreatitis pseudoaneurysms [21, 22].

\section{Treatment strategies}

Initial control of the pseudoaneurysm or any active bleeding may be achieved radiologically or surgically. The range of surgical and nonsurgical treatment options and outcomes is summarised in Tables 2 and 3. In studies that did not select patients based on treatment strategy, embolisation was the first line of management in the majority of them published after $2000(46-92 \%)$ [3, 11]. While some authors preferred angiography (with or without embolisation) as the initial management option [1, 23], others were more selective depending on the presentation [24]. This may be a reflection of local expertise and resource availability.

In postoperative studies, mortality rates in the surgical group were generally higher (50-100\%) than those in the embolisation group (13-50\%). However, this might be expected given that patients requiring early surgical intervention are usually more haemodynamically unstable than those who can wait for angiography.

In the pancreatitis studies, outcomes for surgical and nonsurgical intervention were similar except in the earlier studies. Specifically, the study by De Perrot et al. [14], published in 1999, stood out in that it demonstrated a high mortality rate in patients who were embolised (33\%) compared with a zero mortality rate for the surgical patients. This may reflect relative inexperience with embolisation techniques at a time when surgical therapy was the standard approach.

Obviously, patient selection and timing play important roles in determining the morbidity and mortality of either procedure. Bergert et al. [11] demonstrated this by dividing their patients into those requiring urgent and those requiring semiurgent intervention. Three of nine (33\%) urgent surgical patients died compared with only one of ten $(10 \%)$ semiurgent patients. Herein lies the difficulty in comparing outcomes of surgical and embolisation groups in these case series where the indications and underlying pathologies for embolisation and surgery may be different. This makes statistical comparisons between the outcomes of these two modalities difficult and probably unnecessary. Nonetheless, some authors have attempted statistical analyses. For example, Udd et al. [25], in a series of 33 pseudoaneurysmal bleeds from chronic pancreatitis, found no difference in morbidity and mortality between the 


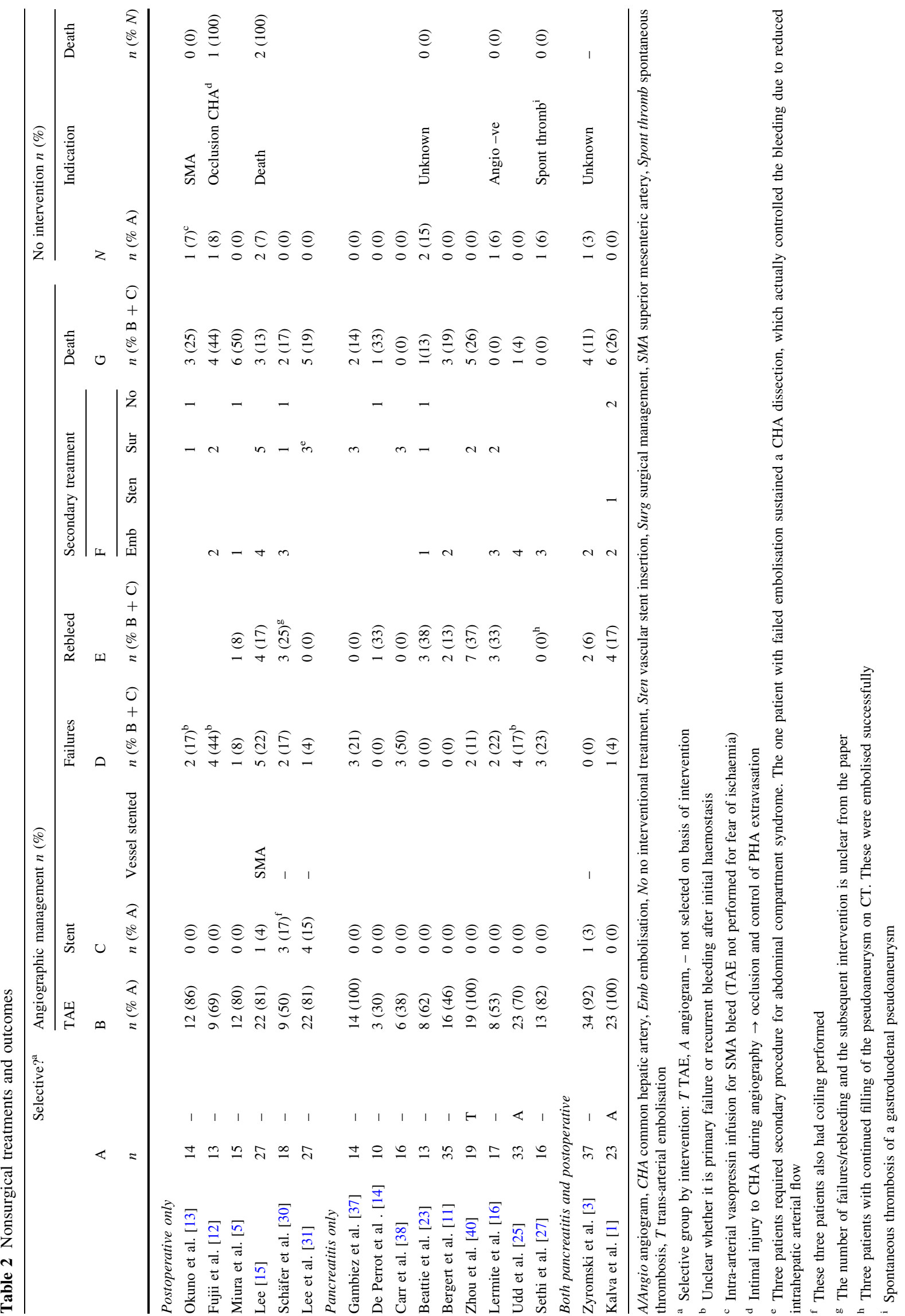


embolisation and surgical groups. Similarly, Roulin et al. [26] performed a meta-analysis comparing laparotomy and interventional radiology for delayed postoperative haemorrhage following pancreatic surgery and, not surprisingly, found a higher mortality rate in the surgical group.

The overall reported success rates of embolisation are high, but this often includes multiple embolisations as well as prolonged supportive treatment. As a single procedure, embolisation alone has a substantial failure rate. The primary failure rate in the studies reviewed ranged from 0 to $50 \%$, with a rebleeding rate of $0-38 \%$ (Table 2). Overall, this translates into a total failure rate of between 6 and $55 \%$, with half of the studies (median of all studies) having a failure rate of greater than $23 \%$. Of the combined 262 patients embolised or stented in all reviewed studies, 51 required a secondary procedure (either re-embolisation or surgery).

Although embolisation was used as first line treatment in most of the recent studies, surgery still remains an important treatment modality, especially in the setting of a haemodynamically compromised patient or when angiographic management fails. The low operation rates in some studies suggest that haemodynamically compromised patients may still be treated radiologically at first $[3,13,15$, 27]. For this to work optimally, the initial radiological intervention should be carried out in an angio-theatre suite, so if it fails, immediate surgical intervention is possible. Other indications for surgery included situations where access to the bleeding vessel was impossible radiologically and when there was failed visualisation or failed embolisation of the bleeding vessel for definitive management of the underlying cause or for other coexisting abdominal pathologies $[3,25,27]$. The indications and outcomes of operative management in the studies reviewed are summarised in Table 3.

The use of stents is a third treatment modality that is being used increasingly for visceral pseudoaneurysms [28, 29]. A stent has the advantage of excluding the pseudoaneurysm while allowing continued flow through the feeding vessel. Only four of the case series reviewed used stents to achieve haemostasis. Lee [15] placed stents in both the common hepatic artery (CHA) (for a short gastroduodenal stump pseudoaneurysm) and the superior mesenteric artery (SMA) in an attempt to avoid end organ ischaemia. Zyromski et al. [3] placed a stent in one patient, but it is unclear in which vessel or the specific indication. The two most recent studies reviewed [30, 31] employed arterial stents as primary intervention for 15 and $17 \%$ of patients, respectively. However, no details were given as to which vessel was stented or the indications. Satisfactory results with stents have been reported by small selective case series. Herzog et al. [29] reported four patients in whom successful haemostasis was achieved with covered stents used for delayed visceral haemorrhage following pancreatic surgery. Similarly, successful haemostasis was achieved in all patients in two smaller case series of four and five patients with hepatic arterial bleeding [28, 32].

Visceral artery stent placement, however, is not without potential complications. The long-term patency and clinical outcomes of stents in this setting are not known [32]. Some authors argue that stent occlusion from intimal hyperplasia may not affect long-term outcome given that it is a slow process which allows time for the formation of collaterals [33]. Such collateralisation did not develop in a patient reported by Lee [15]. The patient developed major thrombosis of the SMA after stent placement resulting in long-term parenteral nutrition due to short-gut syndrome. Other disadvantages of this technique include the possibility of stent infection, exclusion of branches close to the pseudoaneurysm, kinking or misplacement of the stent, and arterial rupture during placement. The lack of availability of small visceral artery "covered" stents may also be a limitation to this approach [5]. The potential complication of stent infection [34] is a major concern in this setting where frequently there is communication with the GIT or the presence of infected necrotic tissue (e.g., necrotising pancreatitis). Infection of a foreign body, such as a stent, may become chronic due to ongoing contamination from an uncontrolled gastrointestinal anastomotic leak. This may be exacerbated if there is a pancreatic anastomotic breakdown where the digestive enzymes contribute to the degradative process.

\section{Influence of vessel type on treatment strategy}

The distribution of involved arteries in each study is summarised in Table 4. As expected, pancreatitis-related pseudoaneurysm formation and bleeding involve most commonly either the splenic artery or the gastroduodenal/ pancreaticoduodenal arterial complex. Post pancreatic surgery cases can affect the same vessels, but the hepatic and mesenteric arteries may also be at risk as a result of an anastomotic leak or an operative injury during radical lymphadenectomy. Unfortunately, it is impossible to glean from the reviewed studies the exact cause of the bleeding and its relationship to arterial distribution.

Splenic, gastroduodenal, and pancreaticoduodenal arteries were the most commonly involved vessels in the studies reviewed. Embolisation of the splenic artery was relatively safe, with only four patients reported to have suffered splenic infarction with infective complications [1, 3]. Also, there were no definite ischaemic complications reported for GDA/PDA (gastroduodenal artery/pancreaticoduodenal artery) embolisation. In a post pancreatoduodenectomy patient, pseudoaneurysm formation in a short GDA stump can be a difficult problem to treat with end 
Table 3 Surgical treatments and outcomes

\begin{tabular}{|c|c|c|c|c|c|c|c|c|c|c|c|c|c|}
\hline & \multicolumn{13}{|c|}{ Surgical management } \\
\hline & \multirow{2}{*}{$\begin{array}{l}\text { A } \\
n\end{array}$} & \multirow{2}{*}{$\begin{array}{l}\text { Surgery } \\
\mathrm{I} \\
n(\% \mathrm{~A})\end{array}$} & \multicolumn{4}{|c|}{ Indication } & \multirow{2}{*}{$\begin{array}{l}\text { Failure } \\
\mathrm{J} \\
n(\% \mathrm{I})\end{array}$} & \multirow{2}{*}{$\begin{array}{l}\text { Rebleed } \\
\mathrm{K} \\
n(\% \mathrm{I})\end{array}$} & \multicolumn{4}{|c|}{ Secondary treatment } & \multirow{2}{*}{$\begin{array}{l}\text { Death } \\
\mathrm{M} \\
n(\% \mathrm{I})\end{array}$} \\
\hline & & & Emer & $\mathrm{Tech}^{\mathrm{a}}$ & Isch & Other & & & Emb & Sten & Sur & No & \\
\hline \multicolumn{14}{|l|}{ Postoperative only } \\
\hline Okuno et al. [13] & 14 & $1(7)$ & & 1 & & & $0(0)$ & $0(0)$ & & & & & $1(100)$ \\
\hline Fujii et al. [12] & 13 & $3(23)$ & 1 & & 2 & & $0(0)$ & $0(0)$ & & & & & $2(66)$ \\
\hline Miura et al. [5] & 15 & $3(20)$ & 2 & & 1 & & $1(33)$ & $0(0)$ & & & & 1 & $3(100)$ \\
\hline Lee [15] & 27 & $2(7)$ & 2 & & & & $0(0)$ & $1(50)$ & & & & 1 & $1(50)$ \\
\hline Schäfer et al. [30] & 18 & $6(39)$ & 2 & & & 4 & $1(17)$ & $3(50)^{\mathrm{b}}$ & & & & & $4(67)$ \\
\hline Lee et al. [31] & 27 & $1(4)$ & 1 & & & & $0(0)$ & $0(0)$ & & & & & $1(100)$ \\
\hline \multicolumn{14}{|l|}{ Pancreatitis only } \\
\hline Gambiez et al. [37] & 14 & $0(0)$ & & & & & - & - & & & & & - \\
\hline De Perrot et al. [14] & 10 & $7(70)$ & 3 & & & $4^{\mathrm{c}}$ & $0(0)$ & $0(0)$ & & & & & $0(0)$ \\
\hline Carr et al. [38] & 16 & $10(63)$ & 6 & & & 4 & $3(30)$ & $1(10)$ & 4 & & & & $3(30)$ \\
\hline Beattie et al. [23] & 13 & $4(31)$ & 3 & 1 & & & $0(0)$ & $0(0)$ & & & & & $0(0)$ \\
\hline Bergert et al. [11] & 35 & $19(54)$ & 9 & & & 10 & $3(16)$ & $4(21)$ & No data & & & & $4(21)$ \\
\hline Zhou et al. [40] & 19 & $0(0)$ & & & & & - & - & & & & & - \\
\hline Lermite et al. [16] & 17 & $7(41)$ & 7 & & & & $0(0)$ & $0(0)$ & & & & & $0(0)$ \\
\hline Udd et al. [25] & 33 & $10(30)$ & & 10 & & & $0(0)$ & $1(10)$ & 1 & & & & $1(10)$ \\
\hline Sethi et al. [27] & 16 & $2(13)$ & 2 & & & & $2(100)$ & $0(0)$ & 1 & & 1 & & $0(0)$ \\
\hline \multicolumn{14}{|c|}{ Both pancreatitis and postoperative } \\
\hline Zyromski et al. [3] & 37 & $1(3)$ & 1 & & & & $1(100)$ & $0(0)$ & & & & 1 & $1(100)$ \\
\hline Kalva et al. [1] & 23 & $0(0)$ & & & & & - & - & & & & & - \\
\hline
\end{tabular}

Emb embolisation, Emerg emergency surgery, Isch fear of ischaemia, Stent vascular stent, Sur surgical management, No no management

a Technical failure includes inability to access or visualise vessel on angiogram and other technical reasons for failure of angioembolisation

${ }^{\mathrm{b}}$ Number of failures/rebleeds unclear from paper. This is the best estimate from text

${ }^{c}$ Operative management was standard treatment at the time

embolisation alone. Hur et al. [35] demonstrated a high rate of rebleeding following the embolisation of the GDA stump and pseudoaneurysm. Even when the CHA also was embolised proximal and distal to the GDA stump, the risk of further bleeding remained significant.

This raises the issue of the safety of embolisation of the CHA and vessels distal to it. Hur et al. [35] found a high incidence of hepatic infarction $(3 / 16,19 \%)$ with this procedure. Although they were able to manage all their cases conservatively, outcomes following embolisation of the hepatic arteries were not as favourable in the other studies reviewed. In the few studies where specific details of the embolised vessels and the clinical outcomes were available, a total of 26 proper hepatic artery (PHA)/CHA and $10 \mathrm{right} / \mathrm{left} / \mathrm{middle}$ hepatic artery (R/L/MHA) embolisations were reported $[3,5,12,13,15,27]$. In those patients, there were seven instances of hepatic failure (of which six died), ten with hepatic infarction and three with a liver abscess. Overall, the morbidity rate was $56 \%$ and the hepatic failure rate of $19 \%$. In another recent study of hepatic artery embolisation, $23 \%(6 / 26)$ of patients developed liver infarction or an abscess. Sato et al. [36] also reported a high morbidity rate $(45 \%)$, hepatic failure rate $(47 \%)$, and mortality rate $(30 \%)$ following hepatic artery embolisation for bleeding after major pancreatic and hepatic surgery. These authors stress the importance of collateral vessel formation requiring multiple embolisations, which increases the risk of fatal complications.

Pseudoaneurysms arising from the SMA are uncommon. These can be managed operatively or by radiological placement of a stent. Miura et al. [5] reported a single case of coil embolisation of an SMA pseudoaneurysm where they managed to maintain patency of the SMA. Unfortunately, the patient subsequently rebled and died. Lee [15] described a patient in whom a SMA stent resulted in thrombosis and the ensuing intestinal ischaemia caused the patient to be dependent on parenteral nutrition. Two cases of SMA pseudoaneurysmal bleeding treated by stent deployment demonstrated control of the bleeding, although one patient died from sepsis due to chronic stent infection 
[34]. Intra-arterial infusion of vasopressin as another radiological treatment option for pseudoaneurysms arising from the SMA has been described with a successful outcome [13]. However, treating a structural anatomical abnormality with a temporary vasospasm agent would seem inadequate.

\section{Rebleeding and the role of definitive surgery}

Rebleeding after embolisation can occur early or late. Early failure may be due to technical problems (e.g., failure to cannulate or localise the bleeding) or to complications during the procedure (e.g., arterial perforation or dissection by the catheter) [14]. From the data presented, a significant proportion of patients rebled at a later date despite an initial successful embolisation (Table 2). Given that the initiating event of the pseudoaneurysm (pancreatic enzymes, local inflammation, or anastomotic leaks) is not dealt with by embolisation, it is likely that these factors contribute to the late rebleeding. While some studies specifically reported 12- or 24-h rebleeding rates, there was great variation in reporting, and in many cases it was difficult to discern between a rebleeding episode and primary failure. When rebleeding was reported, only a few studies provided details about the timing of the bleed and the original presentation or associated pathology. Overall, however, it was clear from the data available that the risk of rebleeding is present days and even months after an initial successful embolisation [14, 24, 30].

Although the data are heterogeneous, several interesting observations can be made from the studies reviewed. First, routine imaging within the first week of the initial embolisation often detects filling of a residual pseudoaneurysm. Sethi et al. [27] used CT scan follow-up at $24 \mathrm{~h}$ and at 1 week. They observed contrast in the aneurysmal sac in $20 \%(3 / 15)$ of their cases despite haemodynamic stability and no clinical evidence of ongoing haemorrhage. The presence of such a residual pseudoaneurysm may contribute to the risk of late bleeding despite apparent initial successful haemostasis. Second, the underlying secondary pathology such as a pseudocyst or a GIT anastomotic leak may increase the risk of rebleeding. This may be related to exposure of the vessels to degradative enzymes such as the lipase-rich fluid in a pseudocyst. This was demonstrated in a small study of patients with severe pancreatitis in which there was a rebleeding rate of $40 \%(2 / 5)$ with a pseudocyst but only $20 \%(1 / 5)$ in those without residual fluid collections [23]. A similar relationship appears to be true also in patients with pancreatitis. There were two studies in which the underlying pathology was specifically treated at or around the time the bleeding was controlled. In the study by Gambiez et al. [37], definitive surgery was performed on most patients at the time of the initial bleeding presentation; this resulted in no rebleeding after a median follow-up of 60 months. Udd et al. [25] treated all pseudocysts endoscopically if they were still present at 6 months and found no rebleeding at the 1-month follow-up.

Of course, there are delayed complications other than rebleeding that can occur after initial control of the bleeding pseudoaneurysm. They are related to the ongoing pathology as well as foreign body (coils or stents) placement. Carr et al. [38] described 3/16 patients with pancreatitis treated for a pseudoaneurysm who developed late complications. One patient required drainage for an infection of a thrombosed pseudocyst and two others had problems with coil migration into the left and right hepatic arteries, respectively, causing left lobar infarction in one. This highlights the importance of investigating and treating any associated pathology as well as dealing with the bleeding pseudoaneurysm. These patients are often unstable and require prioritisation of treatment, usually by controlling the bleeding first, resuscitation second, and then a planned approach to fixing the precipitating pathology. The timing of endoscopic or surgical management of a pseudocyst, or operative intervention for an anastomotic leak, is often difficult because of sepsis or malnutrition. These patients are best managed in a tertiary institution by a multidisciplinary team in a high-dependency or intensive care environment.

Although embolisation has made a dramatic impact on the management of acute bleeding from peripancreatic pseudocysts, radiological management may only be a bridge treatment for some patients. It would be ideal to be able to distinguish a patient as being in one of three groups at the time of presentation: those that can be successfully treated with embolisation alone without the risk of delayed rebleeding, those in whom embolisation may provide only a bridge to possible further surgery, and those who will require early endoscopic or surgical intervention. A management classification of peripancreatic pseudoaneurysms is proposed, based on the following factors that are identified after appropriate imaging (Table 4; Fig. 1A): (1) the vessel of origin, (2) the presence or absence of communication with the GIT, and (3) the presence or absence of pancreatic juice at the bleeding site. The first factor influences the selection of the initial haemostatic strategy (embolisation, stent, of surgery), while the other two factors may influence the decision for definitive endoscopic or surgical management (Fig. 1B).

The arteries from which the pseudoaneurysm arises can be classified into three groups:

1. type I arises from a minor artery but must be at least $5 \mathrm{~mm}$ away from its junction of origin from a type II or III artery 
Table 4 Distribution of artery origins of the pseudoaneurysms in each study

\begin{tabular}{|c|c|c|c|c|c|c|c|}
\hline & \multicolumn{6}{|c|}{ Bleeding point/feeding vessel (main vessel or branches of) } & \multirow[t]{2}{*}{ Total with PA or bleeding point } \\
\hline & SPA & GDA/PDA & CHA/PHA & $\mathrm{L} / \mathrm{R} / \mathrm{M} \mathrm{HA}$ & SMA & Other & \\
\hline \multicolumn{8}{|l|}{ Postoperative only } \\
\hline Okuno et al. [13] & $0(0)$ & $3(21)$ & $0(0)$ & $8(57)$ & $1(7)$ & $2(14)$ & 14 \\
\hline Fujii et al. [12]* & $2(14)$ & $5(36)$ & $2(14)$ & $4(29)$ & $1(7)$ & $0(0)$ & 14 \\
\hline Miura et al. [5] & $0(0)$ & $6(38)$ & $4(25)$ & $2(13)$ & $4(25)$ & $0(0)$ & 16 \\
\hline Lee $[15]$ & $1(4)$ & $12(48)$ & $4(16)$ & $5(20)$ & $1(4)$ & $2(8)$ & 25 \\
\hline Schäfer et al. [30] & $4(22)$ & $2(11)$ & 7 (39) & $3(17)$ & $1(6)$ & $1(6)$ & 18 \\
\hline Lee et al. [31] & No data & & & & & & 27 \\
\hline \multicolumn{8}{|l|}{ Pancreatitis only } \\
\hline Gambiez et al. [37] & $4(29)$ & $8(57)$ & $0(0)$ & $0(0)$ & $0(0)$ & $1(7)$ & 14 \\
\hline De Perrot et al. [14] & $6(60)$ & $3(30)$ & $0(0)$ & $0(0)$ & $0(0)$ & $1(10)$ & 10 \\
\hline Carr et al. [38] & $3(23)$ & $9(70)$ & $0(0)$ & $0(0)$ & $1(8)$ & $0(0)$ & $13^{\mathrm{b}}$ \\
\hline Beattie et al. [23] & $3(23)$ & $8(62)$ & $0(0)$ & $0(0)$ & $0(0)$ & $2(15)$ & 13 \\
\hline Bergert et al. [11] & $10(27)$ & $16(43)$ & $4(11)$ & $0(0)$ & $4(11)$ & $3(8)$ & 37 \\
\hline Zhou et al. [40] & & & & No data & & & 19 \\
\hline Lermite et al. [16] & $6(35)$ & $8(47)$ & $1(6)$ & $0(0)$ & $1(6)$ & $1(6)$ & 17 \\
\hline Udd et al. [25] & $14(42)$ & $19(58)$ & $0(0)$ & $0(0)$ & $0(0)$ & $0(0)$ & 33 \\
\hline Sethi et al. [27] & 7 (44) & $3(19)$ & $3(19)$ & $0(0)$ & $0(0)$ & $3(19)$ & 16 \\
\hline \multicolumn{8}{|c|}{ Both pancreatitis and postoperative } \\
\hline Zyromski et al. [3] & $14(36)$ & $15(38)$ & $5(13)$ & $0(0)$ & $3(8)$ & $2(5)$ & 39 \\
\hline Kalva et al. [1] & $5(21)$ & $10(42)$ & $3(13)$ & $2(8)$ & $0(0)$ & $4(17)$ & 24 \\
\hline
\end{tabular}

CHA common hepatic artery, GDA gastroduodenal artery, $L / R / M H A$ left/right/middle hepatic artery, $P A$ pseudoaneurysm, $P D A$ pancreatoduodenal artery, PHA proper hepatic artery, SMA superior mesenteric artery, SPA splenic artery

a Some patients had multiple PA so the total number of PA may be different from the total number of patients in the study

b Three patients' bleeding point unknown

* Three patients did not demonstrate pseudoaneurysm on angiogram but rather had extravasation in the area of the respective vessels

2. type II arises from a major artery that may be sacrificed without physiological consequences (e.g., splenic and gastroduodenal arteries)

3. type III arises from a major artery that cannot be sacrificed without significant consequences for the patient (e.g., the SMA or the hepatic artery proper)

Pseudoaneurysms can be further subclassified into:

a. type $\mathrm{A}$ where there is no communication with the GIT b. type B where there is a communication with the GIT

In type $\mathrm{A}$, bleeding tends to be low volume, often creating a haematoma within a confined space. In the retroperitoneal space, the expanding haematoma results in rising pressure, which usually compresses the bleeding site. These patients may develop acute renal failure as a result of an abdominal compartment syndrome [39]. In type B, patients frequently have a sentinel bleed that may be followed by a catastrophic haemorrhage. Acute bleeding can be controlled by either embolisation or a stent, but these patients possibly have a higher risk of rebleeding and infection as a result of contamination from the GIT. A more definitive surgical procedure to deal with the pseudoaneurysm may need to be considered after haemodynamic stabilisation with embolisation or an endovascular stent. In patients in whom aneursymal coils and glue or an endovascular stent is exposed to a significant amount of GIT contents, the risk of infection could lead to rebleeding. This risk of rebleeding has to be balanced against the risk of surgical intervention. A long and narrow communication in an elderly patient can be observed, while a short and wide communication in young patient may need a more definitive surgical approach.

We suggest a further subclassification according to exposure to pancreatic juice:

i. type 1 is no exposure to pancreatic juice

ii. type 2 is exposure to pancreatic juice

In a type 2 pseudoaneurysm, enzymes within the pancreatic juice can chemically digest the artery wall. This may lead to further pseudoaneurysm formation or a breaking of the seal between the native arterial wall and the stent or embolisation agent. Patients with a pseudoaneurysm and pseudocyst following pancreatitis and endoscopic transgastric drainage of a pseudocyst may convert type 2 

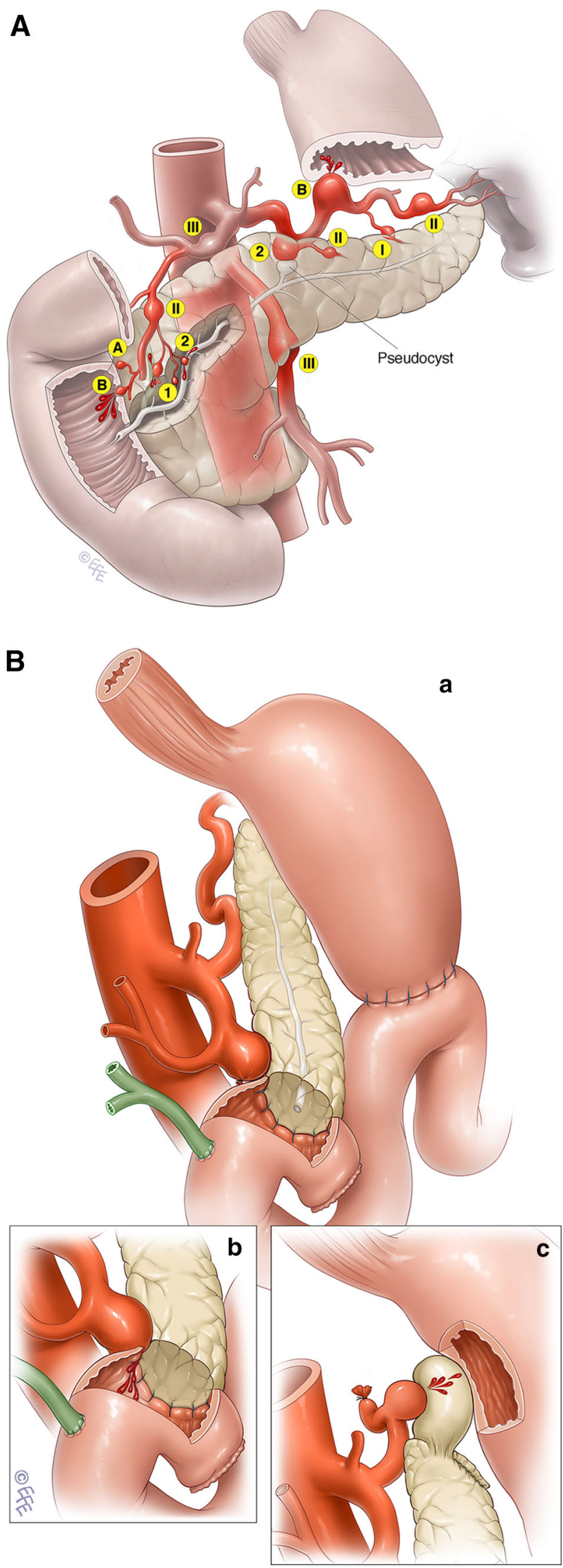

4Fig. 1 Top Examples of the proposed pseudoaneurysm classification based upon the artery type $(I-I I I)$, communication with GIT $(A, B)$, and exposure to pancreatic juice $(1,2)$. Bottom Further specific examples of pseudoaneurysms arising after pancreatic surgery. A A pseudoaneurysm originating from a short GDA stump may arise as a result of a leak from the adjacent pancreatic anastomosis; this is a type IIIB2 aneurysm. B Such a pseudoaneurysm, if it ruptures into the anastomosis, will cause massive gastrointestinal bleeding. C Rupture of a splenic artery pseudoaneurysm into a pseudocyst arising from a pancreatic leak after distal pancreatectomy; this is a type IIA2 pseudoaneurysm

Table 5 Peripancreatic pseudoaneurysm classification system

Type of artery

Communication with Exposure to GIT pancreatic juice

\begin{tabular}{lllll}
\hline I $\quad \begin{array}{c}\text { Minor artery }>5 \mathrm{~mm} \\
\text { away from major } \\
\text { artery }\end{array}$ & A & $\begin{array}{c}\text { No } \\
\text { Communication }\end{array}$ & 1 & $\begin{array}{c}\text { No } \\
\text { exposure }\end{array}$
\end{tabular}

II Major artery which may be sacrificed

B Communication 2 Exposure

III Major artery which cannot be sacrificed

Examples:

Splenic artery pseudoaneurysms (type II) arising from a pancreatic pseudocyst (type 2) with no communication with GIT (type A) are classified as type IIA2 pseudoaneurysm

A GDA stump $(<5 \mathrm{~mm})$ pseudoaneurysm arising from an area of enteropancreatic leak is classified as a type IIIB2 pseudoaneurysm.

into type B. Some of these patients then can be managed conservatively while others may require more definitive surgical management in the long run. The main cause of a pseudoaneurysm following pancreatic surgery is pancreatic fistula. In some patients with an ISGPF type C pancreatic fistula [41] and a pseudoaneurysm, completion pancreatectomy can salvage the situation [42]. Others may have to be managed by diverting the pancreatic juice away from the pseudoaneurysmal vessel.

In summary, peripancreatic pseudoaneurysms may be classified by a combination of the above factors as summarised in Table 5.

\section{Conclusion}

Peripancreatic pseudoaneurysm formation is a major complication that can result following pancreatobiliary surgery or pancreatitis. It is frequently associated with significant morbidity and mortality. Patients who form a peripancreatic pseudoaneurysm are at high risk of rebleeding and often require a definitive surgical procedure after 
initial radiological control by embolisation or placement of a stent. Clinicians need to be aware of the risk of rebleeding at the onset of treatment as this can have a significant impact on the definitive treatment strategy. We propose that the risk of rebleeding depends on infection and chemical digestion. The former is often due to communication with the GIT and the latter is caused by direct contact between the arterial wall and pancreatic juice. The management of this condition is usually a combination of radiology, endoscopy, and surgery and this combination may be assisted by a logical classification system.

Disclosures Tony C. Y. Pang, Richard Maher, Sivakumar Gananadha, Thomas J. Hugh, and Jaswinder S. Samra have no conflicts of interest or financial ties to disclose.

Open Access This article is distributed under the terms of the Creative Commons Attribution License which permits any use, distribution, and reproduction in any medium, provided the original author(s) and the source are credited.

\section{References}

1. Kalva SP, Yeddula K, Wicky S et al (2011) Angiographic intervention in patients with a suspected visceral artery pseudoaneurysm complicating pancreatitis and pancreatic surgery. Arch Surg 146(6):647-652

2. Balthazar EJ, Fisher LA (2001) Hemorrhagic complications of pancreatitis: radiologic evaluation with emphasis on $\mathrm{CT}$ imaging. Pancreatology 1(4):306-313

3. Zyromski NJ, Vieira C, Stecker M et al (2007) Improved outcomes in postoperative and pancreatitis-related visceral pseudoaneurysms. J Gastrointest Surg 11(1):50-55

4. Flati G, Andren-Sandberg A, La Pinta M et al (2003) Potentially fatal bleeding in acute pancreatitis: pathophysiology, prevention, and treatment. Pancreas 26(1):8-14

5. Miura F, Asano T, Amano H et al (2009) Management of postoperative arterial hemorrhage after pancreato-biliary surgery according to the site of bleeding: re-laparotomy or interventional radiology. J Hepatobiliary Pancreat Surg 16(1):56-63

6. Hyare H, Desigan S, Brookes JA et al (2007) Endovascular management of major arterial hemorrhage as a complication of inflammatory pancreatic disease. J Vasc Interv Radiol 18(5): 591-596

7. Sessa C, Tinelli G, Porcu P et al (2004) Treatment of visceral artery aneurysms: description of a retrospective series of 42 aneurysms in 34 patients. Ann Vasc Surg 18(6):695-703

8. Choi S (2004) Delayed hemorrhage after pancreaticoduodenectomy. J Am Coll Surg 199(2):186-191

9. Bergert H, Dobrowolski F, Caffier S et al (2004) Prevalence and treatment of bleeding complications in chronic pancreatitis. Langenbecks Arch Sur 389(6):504-510

10. Nehez L, Tihanyi TF, Huttl K et al (1997) Multimodality treatment of pancreatic pseudoaneurysms. Acta Chir Hung 36(1-4):251-253

11. Bergert H, Hinterseher I, Kersting S et al (2005) Management and outcome of hemorrhage due to arterial pseudoaneurysms in pancreatitis. Surgery 137(3):323-328

12. Fujii Y, Shimada H, Endo I et al (2007) Management of massive arterial hemorrhage after pancreatobiliary surgery: does embolotherapy contribute to successful outcome? J Gastrointest Surg 11(4):432-438
13. Okuno A, Miyazaki M, Ito $\mathrm{H}$ et al (2001) Nonsurgical management of ruptured pseudoaneurysm in patients with hepatobiliary pancreatic diseases. Am J Gastroenterol 96(4):1067-1071

14. de Perrot M, Berney T, Buhler L et al (1999) Management of bleeding pseudoaneurysms in patients with pancreatitis. Br J Surg 86(1):29-32

15. Lee HG, Heo JS, Choi SH, Choi DW (2010) Management of bleeding from pseudoaneurysms following pancreaticoduodenectomy. World J Gastroenterol 16(10):1239-1244

16. Lermite E, Regenet N, Tuech JJ et al (2007) Diagnosis and treatment of hemosuccus pancreaticus: development of endovascular management. Pancreas 34(2):229-232

17. Sato N, Yamaguchi K, Shimizu S et al (1998) Coil embolization of bleeding visceral pseudoaneurysms following pancreatectomy: the importance of early angiography. Arch Surg 133(10):10991102

18. Treckmann J, Paul A, Sotiropoulos GC et al (2008) Sentinel bleeding after pancreaticoduodenectomy: a disregarded sign. J Gastrointest Surg 12(2):313-318

19. de Castro SM, Kuhlmann KF, Busch OR et al (2005) Delayed massive hemorrhage after pancreatic and biliary surgery: embolization or surgery? Ann Surg 241(1):85-91

20. Koukoutsis I, Bellagamba R, Morris-Stiff G et al (2006) Haemorrhage following pancreaticoduodenectomy: risk factors and the importance of sentinel bleed. Dig Surg 23(4):224-228

21. Stabile BE, Wilson SE, Debas HT (1983) Reduced mortality from bleeding pseudocysts and pseudoaneurysms caused by pancreatitis. Arch Surg 118(1):45-51

22. Woods MS, Traverso LW, Kozarek RA et al (1995) Successful treatment of bleeding pseudoaneurysms of chronic pancreatitis. Pancreas 10(1):22-30

23. Beattie GC, Hardman JG, Redhead D et al (2003) Evidence for a central role for selective mesenteric angiography in the management of the major vascular complications of pancreatitis. Am J Surg 185(2):96-102

24. Hsu JT, Yeh CN, Hung CF et al (2006) Management and outcome of bleeding pseudoaneurysm associated with chronic pancreatitis. BMC Gastroenterol 6(1):3

25. Udd M, Leppäniemi AK, Bidel S et al (2007) Treatment of bleeding pseudoaneurysms in patients with chronic pancreatitis. World J Surg 31(3):504-510

26. Roulin D, Cerantola Y, Demartines N et al (2011) Systematic review of delayed postoperative hemorrhage after pancreatic resection. J Gastrointest Surg 15(6):1055-1062

27. Sethi H, Peddu P, Prachalias A et al (2010) Selective embolization for bleeding visceral artery pseudoaneurysms in patients with pancreatitis. Hepatobiliary Pancreat Dis Int 9(6):634-638

28. Stoupis C, Ludwig K, Inderbitzin D et al (2007) Stent grafting of acute hepatic artery bleeding following pancreatic head resection. Eur Radiol 17(2):401-408

29. Herzog T, Suelberg D, Belyaev O et al (2011) Treatment of acute delayed visceral hemorrhage after pancreatic surgery from hepatic arteries with covered stents. J Gastrointest Surg 15(3):496-502

30. Schafer M, Heinrich S, Pfammatter T et al (2011) Management of delayed major visceral arterial bleeding after pancreatic surgery. HPB (Oxford) 13(2):132-138

31. Lee JH, Hwang DW, Lee SY et al (2012) Clinical features and management of pseudoaneurysmal bleeding after pancreatoduodenectomy. Am Surg 78(3):309-317

32. Rami P, Williams D, Forauer A et al (2004) Stent-graft treatment of patients with acute bleeding from hepatic artery branches. Cardiovasc Interv Radiol 28(2):153-158

33. Mansueto G, D'Onofrio M, Iacono C et al (2002) Gastroduodenal artery stump haemorrhage following pylorus-sparing Whipple procedure: treatment with covered stents. Dig Surg 19(3):237-240 
34. Suzuki K, Mori Y, Komada T et al (2009) Stent-graft treatment for bleeding superior mesenteric artery pseudoaneurysm after pancreaticoduodenectomy. Cardiovasc Interv Radiol 32(4):762766

35. Hur S, Yoon CJ, Kang SG et al (2011) Transcatheter arterial embolization of gastroduodenal artery stump pseudoaneurysms after pancreaticoduodenectomy: safety and efficacy of two embolization techniques. J Vasc Interv Radiol 22(3):294-301

36. Sato A, Yamada T, Takase K et al (2011) The fatal risk in hepatic artery embolization for hemostasis after pancreatic and hepatic surgery: importance of collateral arterial pathways. J Vasc Interv Radiol 22(3):287-293

37. Gambiez LP, Ernst OJ, Merlier OA et al (1997) Arterial embolization for bleeding pseudocysts complicating chronic pancreatitis. Arch Surg 132(9):1016-1021

38. Carr JA, Cho JS, Shepard AD et al (2000) Visceral pseudoaneurysms due to pancreatic pseudocysts: rare but lethal complications of pancreatitis. J Vasc Surg 32(4):722-730
39. Milanchi S, Magner D, Lo SK et al (2007) Abdominal compartment syndrome secondary to retroperitoneal hematoma as a complication of ERCP after liver transplantation. Transpl Proc 39(1):169-171

40. Zhou F, Wang C, Xiong J et al (2005) Experience in diagnosis and treatment of bleeding complications in severe acute pancreatitis by TAE. J Huazhong Univ Sci Technol Med Sci 25(2):182184

41. Bassi C, Dervenis C, Butturini G, International Study Group on Pancreatic Fistula Definition et al (2005) Postoperative pancreatic fistula: an international study group (ISGPF) definition. Surgery 138(1):8-13

42. Gueroult S, Parc Y, Duron F et al (2004) Completion pancreatectomy for postoperative peritonitis after pancreatoduodenectomy: early and late outcome. Arch Surg 139(1):16-19 